\title{
Aplikasi Pemupukan Terhadap Pertumbuhan Tanaman Aren Genjah (Arenga pinnata) dan Tanaman Kakao (Theobroma cacao) Pada Penanaman Sistem Jalur
}

\section{Application of Fertilization on the Growth of Early Arenaceous Plants (Arenga pinnata) and Cocoa Plants (Theobroma cacao) in Planting Path Systems}

\author{
Yetti Elidar \\ Tenaga Pendidik Program Studi Agroteknologi, Fakultas Pertanian, Universitas Mulawarman Jl. Pasir Balengkong Kota \\ Samarinda, Kalimantan Timur 75117 \\ email : elidaryetti@gmail.com
}

Diterima : 24 Agustus 2018 Disetujui : 12 Oktober 2018

\begin{abstract}
Planting with a lane system in palm sugar and cacao plants is a technique of plantation cultivation that aims at soil conservation and microenvironment. Plant cultivation in the field needs to get a supply of fertilizer to increase crop productivity. This study aims to determine the effect of giving SP-36 and KCl fertilizer to the best growth of sugar palm and cacao plants in the planting of path systems. The research was conducted on land in Badak Mekar Village, Muara Badak District, Kutai Kartanegara Regency, East Kalimantan. The research method used a Randomized Block Design (RBD) and repeated 4 times. Factorial experiments consisted of 2 factors, as the first factor was SP-36 fertilizer ( $p$ ) consisting of 3 levels: $p 0=0 \mathrm{~kg}$ plant-1 (control); $p 1=0.25 \mathrm{~kg}$ of plant-1; $p 2=0.5$ $\mathrm{kg}$ of plant-1. The second factor was $\mathrm{KCl}(\mathrm{k})$ fertilizer consisting of 3 levels: $\mathrm{k} 0=0 \mathrm{~kg}$ plant-1 (control); $\mathrm{kl}=0.25$ $\mathrm{kg}$ of plant-1; $\mathrm{k} 2=0.5 \mathrm{~kg}$ of plant-1. The variables observed included: (1) Arenaceous plants: increase in caudal circumference, increase in the fifth midrib length, increase in the number of midribs, increase in number of leaflets on the fifth midrib and (2) Cocoa plants: increase in plant height, increase in stem circumference, the number of cocoa fruits, the intensity of pest and disease attacks on cocoa fruit. Observations on each variable were carried out at 3 and 6 months after treatment (mat). Data were analyzed by variance and if there were significant differences, it was followed by the Smallest Significant Difference Test (LSD) at the level of 5\%. The results of the SP-36 fertilizer treatment showed very significant differences in all observation variables in early maturing palm trees and aged 3 bsp and 6 bsp cacao plants. The treatment of SP-36 fertilizer at a dose of $0.5 \mathrm{~kg}$ plant-1 (p2) gave the best growth of early maturing sugar palm plant 6 in the increase of the fifth midrib length, increase in bulb circumference, increase the number of midribs and increase the number of leaflets on the fifth midrib - each $137.17 \mathrm{~cm}, 25.58 \mathrm{~cm}, 3.25$ strands and 39.08 strands. Likewise in the age of 6 bsp cocoa plants SP-36 fertilizer with a dose of $0.5 \mathrm{~kg}$ plant-1 (p2) gave the best growth in plant height increase, increase in stem circumference and number of cocoa fruit, each $18.92 \mathrm{~cm}, 8.25 \mathrm{~cm}$ and 25.25 pieces. The treatment of $\mathrm{KCl}$ fertilizer and the interaction between $\mathrm{SP}-36$ and $\mathrm{KCl}$ fertilizers showed no significant difference in all observation variables in early maturing and cacao plants. Observations of pest and disease attacks on cocoa fruit with the intensity of pest attacks 0.00-23.47\% were included in the category of minor damage and the intensity of disease attacks $0.00-66.30 \%$ which fall into the category of moderate damage.
\end{abstract}

Key words: SP-36 Fertilizer, KCl, Early Sugar Palm, Cocoa, Pathway Planting System

\section{PENDAHULUAN}

Provinsi Kalimantan Timur merupakan salah satu wilayah yang memiliki potensi pengembangan komoditi aren dan kakao. Varietas aren genjah Kutai Timur merupakan plasma nutfah tanaman aren unggul nasional yang telah ditetapkan oleh Menteri Pertanian SK Menteri Pertanian No. 3879 Tahun 2011. Tanaman asli dari Kabupaten Kutai Timur, Kalimantan Timur. Pengembangan tanaman aren di provinsi ini pada tahun 2008, seluas 1.504 ha dengan produktivitas gula merah 4,21 ton ha $^{-1}$.Tahun 2009 luas lahan 1.383 ha dan produktivitas gula merah 3,31 ton ha- ${ }^{-1}$. Tahun 2010 luas lahan 1.273 ha terjadi peningkatan produktivitas gula merah menjadi 4,30 ton ha- . Tahun 2011 terjadi penurunan luas lahan menjadi 1.253 ha dan produktivitas gula merah 1,29ton ha ${ }^{-1}$ (Dinas Perkebunan Provinsi Kaltim, 2013). Sedangkan luas lahan tanaman kakao di Kalimantan Timur saat ini mencapai $23.502 \mathrm{Ha}$ dengan produksi 23.296 ton (Dinas Perkebunan Provinsi Kaltim 2013). Kementerian Pertanian telah menargetkan produksi biji kakao nasional 2 juta ton/tahun pada tahun 2020.

Penanaman dengan sistem jalur pada tanaman aren genjah dan kakao merupakan teknik budidaya tanaman perkebunan dengan pembukaan lahan tanpa bakar yang bertujuan untuk konservasi tanah, lingkungan mikro, melestarikan sumberdaya alam dan lingkungan serta meningkatkan pendapatan petani. Dalam pengembangan tanaman aren permasalahan pokok yaitu belum dibudidayakannyatanaman aren dengan sentuhan teknologi dan merupakan 
pertanaman tradisional. Demikian pula pada budidaya kakao di Kaltim juga mengalami beberapa kendala teknis seperti pengelolaan usaha tani yang kurang baik, tanaman banyak yang sudah tua dan rusak; tanaman kurang terpelihara serta adanya gangguan hama dan penyakit; bencana alam (banjir); dan kekeringan serta terbakar.

Melihat potensi lahan terutama kebun, perlu mendapat sentuhan inovasi teknologi guna meningkatkan produktivitasnya di lapangan yaitu diperlukan pasokan unsur hara melalui pemupukan sesuai dosis dan umur tanaman. Pemberian pupuk ke dalam tanah akan menambah satu atau lebih unsur hara tanah dan ini akan mengubah keseimbangan hara lainnya (Silalahi et al., 2006).

Pupuk SP-36 merupakan pupuk $\mathrm{P}$ yang mengandung $36 \% \quad \mathrm{P}_{2} \mathrm{O}_{5}$. Fungsi $\mathrm{P}$ dalam tanaman yaitu dapat mempercepat pertumbuhan akar semai, dapat memepercepat serta memperkuat pertumbuhan tanaman muda menjadi tanaman dewasa pada umumnya, dapat mempercepat pembungaan dan pemasakan buah dan biji dan dapat meningkatkan produksi bijibijian (Sutejo, 2002). Pada awal pertumbuhan tanaman, pupuk fosfat sangat berperan sebagai komponen beberapa enzim dan ketersediaan asam nukleat. Sedangkan pada akhir pertumbuhan sangat berperan dalam pembentukan biji dan buah (Hanafiah, 2005).

\section{BAHAN DAN METODE}

Penelitian ini dilaksanakan di lahan petani di Desa Badak Mekar Kecamatan Muara Badak Kabupaten Kutai Kartanegara dan Laboratorium Hama dan Penyakit Tanaman (HPT) serta Laboratorium Ilmu Tanah Fakultas Pertanian, Universitas Mulawarman. Bahan yang digunakan dalam penelitian ini adalah tanaman aren genjah dan tanaman kakao varietas Sulawesi 1 umur 2 tahun, pupuk SP-36, pupuk $\mathrm{KCl}$ dan pupuk urea. Rancangan penelitian yang digunakan adalah Rancangan Acak Kelompok (RAK) dengan percobaan faktorial $(3 \times 3)$ dan diulang sebanyak 4 kali. Percobaan faktorial terdiri dari 2 faktor, sebagai faktor pertama adalah pupuk SP-36 (P) terdiri dari 3 taraf: $\mathrm{p}_{0}=$ $0 \mathrm{~kg}$ tanaman $^{-1}$ (kontrol); $\mathrm{p}_{1}=0,25 \mathrm{~kg}$ tanaman $^{-1}$; $\mathrm{p}_{2}=0,5 \mathrm{~kg} \operatorname{tanaman}^{-1}$. Faktor kedua adalah
Penanaman dengan sistem jalur dapat mempengaruhi kondisi iklim mikro yang dapat memacu perkembangan patogen dan menurunkan hasil tanaman kakao serta menjadi habitat berkembangnya hama pada tanaman aren genjah. Sehingga diperlukan pupuk K karena unsur $\mathrm{K}$ di dalam tanaman berperan memperkuat sel dan jaringan tanaman, memperbesar daya ketahanan terhadap gangguan hama dan penyakit, memperkuat batang tanaman serta membuat tanaman lebih tahan dari gangguan stres. Pupuk $\mathrm{KCl}$ yang merupakan pupuk $\mathrm{K}$ dengan kandungan $60 \% \mathrm{~K}_{2} \mathrm{O}$ sangat dianjurkan karena dapat meningkatkan daya tahan tanaman terhadap hama dan serangan penyakit.

Kerugian yang diakibatkan oleh hama tersebut mencapai ratusan milyar rupiah per tahun (Pusat Penelitian Kopi dan Kakao Indonesia [PPKKI], 2010). Serangan penyakit pembuluh kayu (vascular streak dieback = VSD) dapat menyebabkan penurunan produktivitas kakao sebesar 40\% (Manggabarani, 2011). Penyakit penting lainnya, yaitu busuk buah Phytophthora (BBP) dapat menyebabkan kehilangan hasil antara 20-30\% pertahun (Wood $\&$ Lass, 1985), bahkan hingga > 40\% (Pusat Penelitian Kopi dan Kakao Indonesia, 2010). Berdasarkan uraian tersebut di atas, maka perlu dilakukan penelitian tentang respon pertumbuhan tanaman aren genjah dan tanaman kakao pada pemberian pupuk SP-36 dan $\mathrm{KCl}$ pada penanaman sistem jalur.

pupuk $\mathrm{KCl}(\mathrm{k})$ terdiri dari 3 taraf: $\mathrm{k}_{0}=0 \mathrm{~kg}$ tanaman $^{-1}$ (kontrol); $\mathrm{k}_{1}=0,25 \mathrm{~kg}$ tanaman $^{-1} ; \mathrm{k}_{2}=$ $0,5 \mathrm{~kg} \operatorname{tanaman}^{-1}$. Pelaksanaan penelitian meliputi penyiapan lahan, pembuatan lubang tanam, penanaman bibit aren genjah dan bibit kakao, pemupukan dasar, perlakuan pupuk SP36 dan KCL dan pemeliharaan tanaman meliputi pengendalian gulma dilakukan setiap bulan sedangkan pembumbunan 3 bulan sekali. Parameter pengamatan meliputi : tanaman aren berupa pertambahan panjang pelepah ke-5, pertambahan lingkar bonggol, pertambahan jumlah pelepah dan pertambahan jumlah anak daun pada pelepah ke-5 serta tanaman kakao berupa pertambahan tinggi tanaman, pertambahan lingkar batang, jumlah buah dan intensitas serangan hama dan penyakit pada buah kakao dengan rumus : $I S=\frac{n}{N} \times 100 \%$ 


\section{HASIL DAN PEMBAHASAN}

\section{Pengaruh Pemberian Pupuk SP-36 Terhadap Pertumbuhan Tanaman Aren Genjah dan Kakao}

Berdasarkan hasil sidik ragam perlakuan pupuk SP-36 menunjukkan berbeda sangat nyata terhadap tanaman aren genjah umur 3 bsp dan 6 bsp pada pertambahan lingkar bonggol, pertambahan panjang pelepah ke-5, pertambahan jumlah pelepah dan pertambahan jumlah anak daun pada pelepah ke-5. Perlakuan pupuk SP-36 juga menunjukkan berbeda sangat nyata terhadap tanaman kakao umur 3 bsp dan 6 bsp pada pertambahan tinggi tanaman, pertambahan lingkar batang dan pertambahan jumlah buah kakao.

Pengaruh pemberian pupuk SP-36 terhadap tanaman aren genjah umur 3 bsp dan 6 bsp pada pertambahan panjang pelepah ke-5, pertambahan lingkar bonggol, pertambahan jumlah pelepah dan pertambahan jumlah anak daun pada pelepah ke-5 dapat dilihat pada gambar 1, 2, 3 dan 4 .

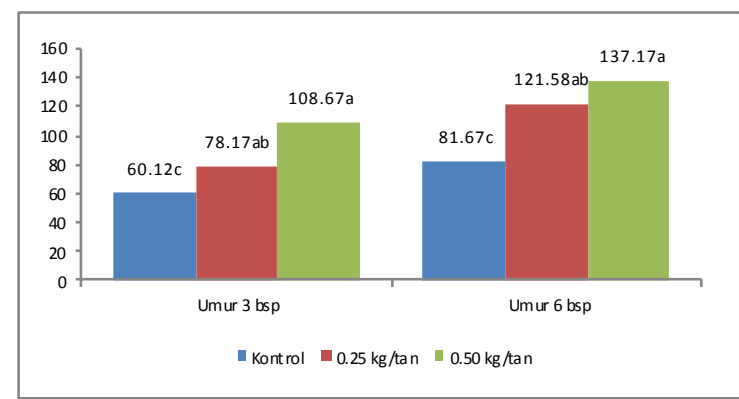

Gambar 1. Pertambahan Panjang Pelepah ke-5

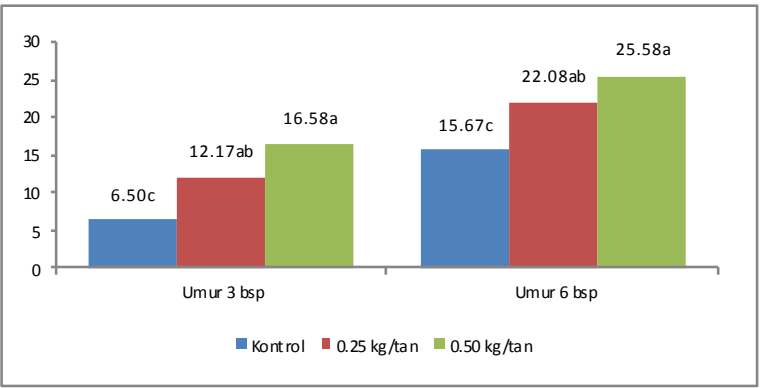

Gambar 2. Pertambahan Lingkar Bonggol

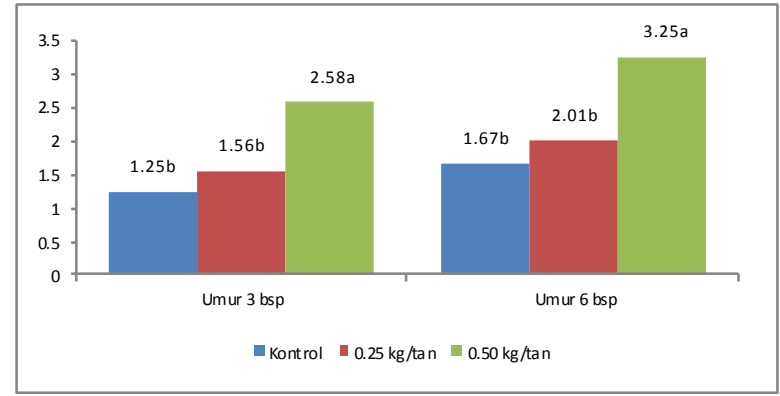

Gambar 3. Pertambahan Jumlah Pelepah

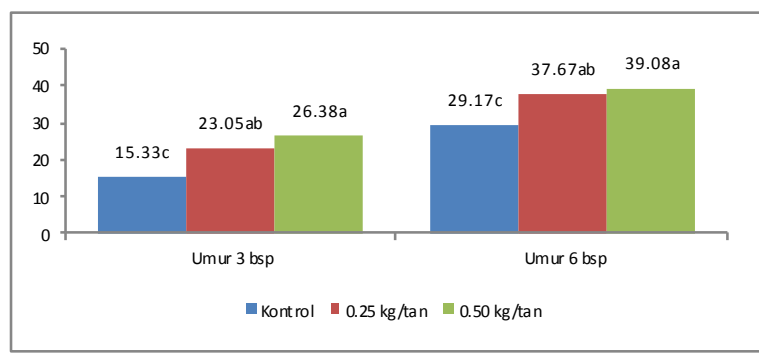

Gambar 4. Pertambahan Jumlah Anak Daun Pada Pelepah ke-5

Berdasarkan hasil uji BNT taraf 5\% terhadap pertambahan panjang pelepah ke-5 pada tanaman aren genjah umur 3 bsp menunjukkan bahwa perlakuan p0 berbeda nyata dengan p2 tetapi berbeda tidak nyata dengan p1. Perlakuan p1 berbeda tidak nyata dengan p2. Rata-rata pertambahan panjang pelepah ke-5 terpanjang ditunjukkan pada perlakuan p2 yaitu $108.67 \mathrm{~cm}$ dan yang terpendek pada perlakuan t0 yaitu $60.12 \mathrm{~cm}$.

Berdasarkan hasil uji BNT taraf 5\% terhadap pertambahan lingkar bonggol pada tanaman aren genjah umur 3 bsp menunjukkan bahwa perlakuan p0 berbeda nyata dengan $\mathrm{p} 2$ tetapi berbeda tidak nyata dengan $\mathrm{p} 1$. Perlakuan $\mathrm{p} 1$ berbeda tidak nyata dengan p2. Rata-rata pertambahan lingkar bonggol tertinggi ditunjukkan pada perlakuan p2 yaitu $16.58 \mathrm{~cm}$ dan yang terendah pada perlakuan t0 yaitu 6.50 $\mathrm{cm}$.

Berdasarkan hasil uji BNT taraf 5\% terhadap pertambahan jumlah pelepah pada tanaman aren genjah umur 3 bsp menunjukkan bahwa perlakuan $\mathrm{p} 0$ berbeda nyata dengan $\mathrm{p} 2$ tetapi berbeda tidak nyata dengan p1. Perlakuan p1 berbeda tidak nyata dengan p2. Rata-rata pertambahan jumlah pelepah tertinggi ditunjukkan pada perlakuan p2 yaitu 2.58helai dan yang terendah pada perlakuan t0 yaitu 1.25 helai.

Berdasarkan hasil uji BNT taraf 5\% terhadap pertambahan jumlah anak daun pada pelepah ke5 pada tanaman aren genjah umur 3 bsp menunjukkan bahwa perlakuan $\mathrm{p} 0$ berbeda nyata dengan $\mathrm{p} 2$ tetapi berbeda tidak nyata dengan $\mathrm{p} 1$. Perlakuan p1 berbeda tidak nyata dengan $\mathrm{p} 2$. Rata-rata pertambahan jumlah anak daun pada pelepah ke-5 tertinggi ditunjukkan pada perlakuan p2 yaitu 26.38 helai dan yang terendah pada perlakuan t0 yaitu 15.33 helai.

Berdasarkan hasil uji BNT taraf 5\% terhadap pertambahan panjang pelepah ke-5 pada tanaman aren genjah umur 6 bsp menunjukkan bahwa perlakuan p0 berbeda nyata dengan p2 tetapi berbeda tidak nyata dengan p1. Perlakuan p1 berbeda tidak nyata dengan p2. Rata-rata pertambahan panjang pelepah ke-5 terpanjang 
ditunjukkan pada perlakuan p2 yaitu $137.17 \mathrm{~cm}$ dan yang terpendek pada perlakuan t0 yaitu $81.67 \mathrm{~cm}$.

Berdasarkan hasil uji BNT taraf 5\% terhadap pertambahan lingkar bonggol pada tanaman aren genjah umur 6 bsp menunjukkan bahwa perlakuan p0 berbeda nyata dengan p2 tetapi berbeda tidak nyata dengan $\mathrm{p} 1$. Perlakuan $\mathrm{p} 1$ berbeda tidak nyata dengan p2. Rata-rata pertambahan lingkar bonggol tertinggi ditunjukkan pada perlakuan p2 yaitu $25.58 \mathrm{~cm}$ dan yang terendah pada perlakuan t0 yaitu 15.67 $\mathrm{cm}$.

Berdasarkan hasil uji BNT taraf 5\% terhadap pertambahan jumlah pelepah pada tanaman aren genjah umur 6 bsp menunjukkan bahwa perlakuan p0 berbeda nyata dengan p2 tetapi berbeda tidak nyata dengan $\mathrm{p} 1$. Perlakuan $\mathrm{p} 1$ berbeda tidak nyata dengan p2. Rata-rata pertambahan jumlah pelepah tertinggi ditunjukkan pada perlakuan p2 yaitu 3.25helai dan yang terendah pada perlakuan t0 yaitu 1.67 helai.

Berdasarkan hasil uji BNT taraf 5\% terhadap pertambahan jumlah anak daun pada pelepah ke5 pada tanaman aren genjah umur 6 bsp menunjukkan bahwa perlakuan $\mathrm{p} 0$ berbeda nyata dengan $\mathrm{p} 2$ tetapi berbeda tidak nyata dengan $\mathrm{p} 1$. Perlakuan $\mathrm{p} 1$ berbeda tidak nyata dengan $\mathrm{p} 2$. Rata-rata pertambahan jumlah anak daun pada pelepah ke-5 tertinggi ditunjukkan pada perlakuan p2 yaitu 39.08 helai dan yang terendah pada perlakuan t0 yaitu 29.17 helai.

Pengaruh pemberian pupuk SP-36 terhadap tanaman kakao umur 3 bsp dan 6 bsp pada pertambahan tinggi tanaman, pertambahan lingkar batang, dan pertambahan jumlah buah kakao dapat dilihat pada gambar 5, 6 dan 7 .

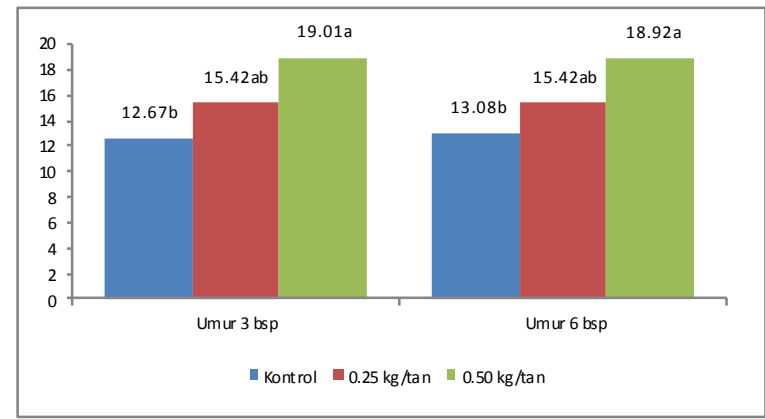

Gambar 5. Pertambahan Tinggi Tanaman

Berdasarkan hasil uji BNT taraf 5\% terhadap pertambahan tinggi tanaman tanaman kakao umur 3 bsp menunjukkan bahwa perlakuan p0 berbeda nyata dengan $\mathrm{p} 2$ tetapi berbeda tidak nyata dengan $\mathrm{p} 1$. Perlakuan $\mathrm{p} 1$ berbeda tidak nyata dengan $\mathrm{p} 2$. Rata-rata pertambahan tinggi tanaman tertinggi ditunjukkan pada perlakuan p2 yaitu $19.01 \mathrm{~cm}$ dan yang terendah pada perlakuan t0 yaitu $12.67 \mathrm{~cm}$.

Berdasarkan hasil uji BNT taraf 5\% terhadap pertambahan lingkar batang tanaman kakao umur 3 bsp menunjukkan bahwa perlakuan p0 berbeda nyata dengan $\mathrm{p} 2$ tetapi berbeda tidak nyata dengan $\mathrm{p} 1$. Perlakuan $\mathrm{p} 1$ berbeda tidak nyata dengan $\mathrm{p} 2$. Rata-rata pertambahan lingkar batang tertinggi ditunjukkan pada perlakuan p2 yaitu $5.33 \mathrm{~cm}$ dan yang terendah pada perlakuan t0 yaitu $2.75 \mathrm{~cm}$.

Berdasarkan hasil uji BNT taraf 5\% terhadap jumlah buah kakao umur 3 bsp menunjukkan bahwa perlakuan $\mathrm{p} 0$ berbeda nyata dengan $\mathrm{p} 2$ tetapi berbeda tidak nyata dengan $\mathrm{p} 1$. Perlakuan p1 berbeda tidak nyata dengan p2. Rata-rata jumlah buah tertinggi ditunjukkan pada perlakuan p2 yaitu 10.83 buah dan yang terendah pada perlakuan t0 yaitu 4.42 buah.

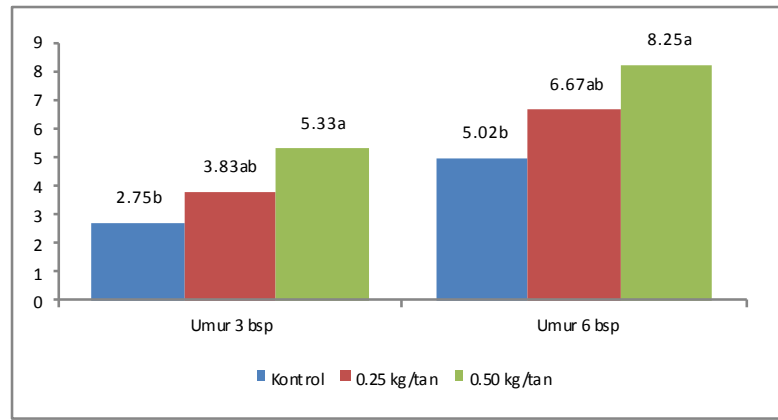

Gambar 6. Pertambahan Lingkar Batang

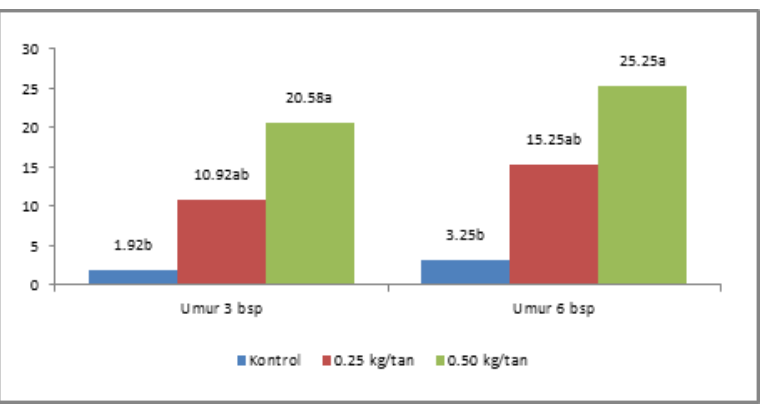

Gambar 7. Jumlah Buah Kakao

Berdasarkan hasil uji BNT taraf 5\% terhadap pertambahan tinggi tanaman tanaman kakao umur 6 bsp menunjukkan bahwa perlakuan p0 berbeda nyata dengan p2 tetapi berbeda tidak nyata dengan $\mathrm{p} 1$. Perlakuan $\mathrm{p} 1$ berbeda tidak nyata dengan $\mathrm{p} 2$. Rata-rata pertambahan tinggi tanaman tertinggi ditunjukkan pada perlakuan $\mathrm{p} 2$ yaitu $18.92 \mathrm{~cm}$ dan yang terendah pada perlakuan t0 yaitu $13.08 \mathrm{~cm}$.

Berdasarkan hasil uji BNT taraf 5\% terhadap pertambahan lingkar batang pada tanaman kakao umur 6 bsp menunjukkan bahwa perlakuan p0 berbeda nyata dengan p2 tetapi berbeda tidak nyata dengan $\mathrm{p} 1$. Perlakuan $\mathrm{p} 1$ berbeda tidak nyata dengan $\mathrm{p} 2$. Rata-rata pertambahan lingkar batang tertinggi ditunjukkan pada perlakuan p2 
yaitu $8.25 \mathrm{~cm}$ dan yang terendah pada perlakuan t0 yaitu $5.02 \mathrm{~cm}$.

Berdasarkan hasil uji BNT taraf 5\% terhadap jumlah buah kakao umur 6 bsp menunjukkan bahwa perlakuan $\mathrm{p} 0$ berbeda nyata dengan p2 tetapi berbeda tidak nyata dengan p1. Perlakuan p1 berbeda tidak nyata dengan p2. Rata-rata jumlah buah tertinggi ditunjukkan pada perlakuan $\mathrm{p} 2$ yaitu 16.17 buah dan yang terendah pada perlakuan t0 yaitu 8.08 buah.

Pemberian pupuk SP-36 berbeda nyata terhadap tanaman aren genjah dan kakao pada umur 3 bsp dan 6 bsp. Hal ini diduga bahwa tanaman dapat memanfaatkan pupuk SP-36 untuk mendukung pertumbuhan tanaman. Hasil analisa tanah menunjukkan bahwa kandungan unsur $\mathrm{P}$ tersedia di dalam tanah sebesar $9.60 \mathrm{ppm}$ dan termasuk kedalam kategori rendah. Sehingga pemberian pupuk SP-36 dapat meningkatkan ketersediaan unsur $\mathrm{P}$ di dalam tanah dan digunakan dalam mendukung pertumbuhan tanaman aren genjah dan tanaman kakao.

Sesuai pendapat Pranata (2010) pemupukan $\mathrm{P}$ selain untuk menggantikan $\mathrm{P}$ yang terangkut tanaman juga untuk meningkatkan kadar $\mathrm{P}$ tanah sehingga diharapkan pada waktu yang akan datang (status kandungan $\mathrm{P}$ tanah) berubah dari rendah dan sedang menjadi tinggi dengan kata

\section{Pengaruh Pemberian Pupuk KCl Terhadap Pertumbuhan Tanaman Aren Genjah dan Kakao}

Berdasarkan hasil sidik ragam perlakuan pupuk $\mathrm{KCl}$ berpengaruh tidak nyata terhadap tanaman aren genjah dan tanaman kakao umur 3 bsp dan 6 bsp pada semua variabel pengamatan. lain pemupukan $\mathrm{P}$ yang lebih tinggi dari kebutuhan tanaman dapat memperkaya tanah.

Perlakuan pupuk SP-36 dengan pemberian dosis $0.5 \mathrm{~kg}$ tanaman ${ }^{-1}$ memberikan pertumbuhan tanaman aren genjah dan kakao yang terbaik. Hal ini disebabkan pemberian pupuk SP-36 dalam jumlah yang banyak dapat mendukung pertumbuhan tanaman meskipun unsur hara yang terkandung dalam pupuk SP-36 belum diserap secara maksimal. Unsur fosfor yang merupakan unsur penting dalam transfer energi, berperan dalam fotosintesis, metabolism asam lemak, glikolisis, dan oksidasi biologis. Menurut soepardi (2001) unsur P bagi tanaman berguna untuk merangsang pertumbuhan akar benih dan tanaman muda. Sutedjo (2004) menambahkan bahwa fungsi dari pupuk P bagi tanaman antara lain dapat mempercepat serta memperkuat pertumbuhan tanaman muda menjadi dewasa, mempercepat pembungaan dan pemasakan buah, biji serta dapat meningkatkan produksi bijibijian.

Muhadjir dalam Baroroh (2001) menyatakan bahwa pemberian unsur hara $\mathrm{P}$ ke dalam tanah dapat meningkatkan penyerapan unsur $\mathrm{N}$ oleh tanaman, sehingga unsur $\mathrm{N}$ tersebut turut mempengaruhi pertumbuhan tanaman terutama pada fase vegetatif.

Pengaruh pemberian Pupuk $\mathrm{KCl}$ terhadap tanaman aren genjah dan tanaman kakao umur 3 bsp dan 6 bsp dapat dilihat pada Tabel 1 dan Tabel 2.

Tabel 1. Pengaruh Pemberian Pupuk KCl Terhadap Tanaman Aren Genjah Pada Rata-rata Pertambahan Panjang Pelepah ke-5, Pertambahan Lingkar Bonggol, Pertambahan Jumlah Pelepah dan Pertambahan Jumlah Anak Daun Pada Pelepah ke-5.

\begin{tabular}{ccccccccc}
\hline \multirow{2}{*}{$\begin{array}{c}\text { Perlakuan } \\
\text { Pupuk KCl }\end{array}$} & \multicolumn{2}{c}{$\begin{array}{c}\text { Panjang Pelepah } \\
\text { ke-5 }\end{array}$} & \multicolumn{2}{c}{$\begin{array}{c}\text { Lingkar } \\
\text { Bonggol }\end{array}$} & \multicolumn{2}{c}{ Jumlah Pelepah } & \multicolumn{2}{c}{$\begin{array}{c}\text { Jumlah Anak Daun } \\
\text { Pada Pelepah ke-5 }\end{array}$} \\
\cline { 2 - 9 } & $3 \mathrm{bsp}$ & $6 \mathrm{bsp}$ & $3 \mathrm{bsp}$ & $6 \mathrm{bsp}$ & $3 \mathrm{bsp}$ & $6 \mathrm{bsp}$ & $3 \mathrm{bsp}$ & $6 \mathrm{bsp}$ \\
\cline { 2 - 9 } & tn & tn & tn & tn & tn & tn & tn & tn \\
\hline $\mathrm{k}_{0}$ & 73.42 & 98.00 & 10.83 & 19.83 & 1.42 & 1.92 & 23.66 & 34.33 \\
$\mathrm{k}_{1}$ & 81.33 & 112.83 & 12.00 & 21.25 & 1.75 & 2.33 & 24.43 & 35.25 \\
$\mathrm{k}_{2}$ & 92.33 & 129.58 & 12.43 & 22.25 & 2.25 & 2.67 & 25.00 & 36.33 \\
\hline
\end{tabular}

Tabel 2. Pengaruh Pemberian Pupuk KCl terhadap Tanaman Kakao Pada Rata-rata Pertambahan Tinggi Tanaman, Pertambahan Lingkar Batang, Jumlah Buah.

\begin{tabular}{ccccccc}
\hline Perlakuan & \multicolumn{2}{c}{ Tinggi Tanaman } & \multicolumn{2}{c}{ Lingkar Batang } & \multicolumn{2}{c}{ Jumlah Buah } \\
\cline { 2 - 7 } Pupuk KCl & 3 bsp & 6 bsp & 3 bsp & 6 bsp & 3 bsp & 6 bsp \\
\cline { 2 - 7 } & tn & tn & tn & tn & tn & tn \\
\hline $\mathrm{k}_{0}$ & 14.58 & 14.83 & 3.50 & 6.17 & 1.92 & 3.25 \\
$\mathrm{k}_{1}$ & 15.58 & 15.75 & 4.00 & 6.75 & 10.92 & 15.25 \\
$\mathrm{k}_{2}$ & 16.92 & 16.83 & 4.42 & 7.00 & 20.58 & 25.25 \\
\hline
\end{tabular}


Perlakuan pupuk $\mathrm{KCl}$ berpengaruh tidak nyata terhadap tanaman aren genjah dan tanaman kakao pada semua parameter pengamatan. Hal ini diduga tanaman aren dan tanaman kakao tidak menyerap unsur hara $\mathrm{K}$ yang terkandung dalam pupuk $\mathrm{KCl}$ karena ketersediaan unsur $\mathrm{K}$ yang terdapat dalam tanah termasuk kedalam kategori sangat tinggi sehingga pemberian pupuk $\mathrm{KCl}$ tidak berpengaruh. Menurut Siagian (2012) terdapat kesamaan sifat antara $\mathrm{P}$ dengan $\mathrm{K}$ yaitu apabila tersedia dalam jumlah yang sangat tinggi menyebabkan pemberian pupuk tidak berpengaruh. Selanjutnya Soepartini (1994) menambahkan bahwa makin rendah kandungan $\mathrm{P}$ dalam tanah, maka makin banyak diperlukan pupuk. Sedangkan semakin tinggi $\mathrm{P}$ dalam tanah, maka tanah tersebut semakin tidak memerlukan pupuk.

Subandi (2013) menyatakan bahwa berdasarkan analisis tanah, pembagian kelas status K terdiri dari lima kelas, untuk kelas status $\mathrm{K}$ sangat tinggi, lahan dianjurkan tidak dipupuk $\mathrm{KCl}$, sedangkan untuk kelas yang lain, takaran pupuk $\mathrm{KCl}$ dapat ditetapkan sesuai dengan target produktivitas tanaman dengan tetap mempertahankan kesuburan $\mathrm{K}$ tanah. Kelebihan $\mathrm{K}$ yang diserap tanaman kurang bermanfaat bagi peningkatan pertumbuhan tanaman.

Selain itu diduga adanya faktor internal berupa genetik dan varietas tanaman itu sendiri serta faktor eksternal yang berupa iklim, suhu, cahaya, dan air ikut tergolong meningkatkan pertumbuhan tanaman. Sesuai dengan pendapat Ramli (2014), menyatakan bahwa pertumbuhan tanaman disebabkan oleh beberapa faktor diantaranya faktor eksternal berupa hara yang berperan didalamnya dan air yang ikut mengangkut hara dari dalam tanah, sedangkan faktor internal yaitu dari jenis atau varietas tanaman itu sendiri.

Keberadaan unsur kalium harus tetap dijaga keseimbangannya dengan unsur hara lain (Mungnisjah dan Setiawan 2004). Unsur hara K dan $\mathrm{P}$ saling ketergantungan, unsur $\mathrm{K}$ berfungsi sebagai media transportasi yang membawa harahara dari akar termasuk hara $\mathrm{P}$ ke daun dan

\section{Pengaruh Interaksi Antara Pupuk SP-36 dan KCl Terhadap Pertumbuhan Tanaman Aren Genjah dan Kakao}

Berdasarkan hasil sidik ragam interaksi antara perlakuan pupuk SP-36 dan pupuk $\mathrm{KCl}$ berbeda tidak nyata terhadap tanaman aren genjah dan tanaman kakao pada semua variabel pengamatan. Sesuai pendapat steel dan Torrie (1993), bilamana dua faktor tidak menunjukkan pengaruh maka dapat disimpulkan bahwa kedua mentranslokasi asimilat dari daun ke seluruh jaringan tanaman. Agar proses transportasi unsur hara maupun asimilat dalam tanaman dapat berlangsung optimal maka unsur $\mathrm{K}$ dalam tanaman harus optimal (Taufiq, 2002).

Unsur hara (N, P, dan K) berkaitan satu sama lain (Hadisaputro, 2005). Marschner (1986) menambahkan dua unsur hara atau lebih yang berbeda mempunyai kedekatan ukuran dan jumlah muatan akan berperilaku: (1) saling menggantikan (bersubtitusi), (2) saling berkompetisi dalam proses penyerapan, dan (3) saling menghilangkan kemampuan selektivitas akar tanaman dalam menyerap unsur-unsur hara tersebut.

Menurut Haris dan Krestiani (2005). kalium berperan penting dalam proses fisiologis, metabolisme karbohidrat, pembentukan, pemecahan dan translokasi pati. Kadar kalium yang cukup pada tanaman mengakibatkan pembentukan dan pembesaran ukuran sel pada bagian tanaman secara normal, sehingga meningkatkan laju proses fotosintesis dimana unsur kalium berperan dalam fotofosforilasi dalam proses fotosintesis. Tanaman yang mendapatkan $\mathrm{K}$ cukup akan tumbuh lebih cepat karena $\mathrm{K}$ dapat memelihara tekanan turgor sel secara konstan. Tekanan turgor sel yang konstan dapat memacu pembesaran sel-sel yang menyusun jaringan meristem, yang mana jaringan meristem ini berfungsi menghasilkan sel-sel baru diujung tanaman yang dapat meningkatkan pertambahan tinggi tanaman. Pertambahan tinggi tanaman ini termasuk dalam pertumbuhan primer, pertumbuhan primer terjadi sebagai hasil pembelahan sel jaringan maristem primer. Pertumbuhan primer diakibatkan oleh aktivitas maristem apikal yang terdapat pada ujung akar dan pucuk tunas, menghasilkan sel-sel bagi tumbuhan untuk tumbuh memanjang (Champbell, 2002).

Roesmarkam dan Yuwono menyatakan bahwa kalium tersedia dalam tanah tidak selalu tetap dalam keadaan tersedia, tetapi masih berubah menjadi bentuk yang lambat untuk diserap oleh tanaman (slowly available).

faktor tersebut bertindak bebas tidak saling mempengaruhi. Pengaruh pemberian interaksi antara pupuk SP-36 dan pupuk $\mathrm{KCl}$ terhadap tanaman aren genjah dan tanaman kakao umur 3 bsp dan 6 bsp dapat dilihat pada Tabel 3 dan Tabel 4. 
Tabel 3. Pengaruh Interaksi Pupuk SP-36 dan $\mathrm{KCl}$ terhadap Tanaman Aren Genjah Pada Rata-rata Pertambahan Panjang Pelepah ke-5, Pertambahan Lingkar Bonggol, Pertambahan Jumlah Pelepah dan Pertambahan Jumlah Anak Daun Pada Pelepah ke-5.

\begin{tabular}{ccccccccc}
\hline & \multicolumn{3}{c}{$\begin{array}{c}\text { Panjang Pelepah ke- } \\
5\end{array}$} & \multicolumn{2}{c}{ Lingkar Bonggol } & \multicolumn{2}{c}{ Jumlah Pelepah } & \multicolumn{2}{c}{$\begin{array}{c}\text { Jumlah Anak Daun } \\
\text { Pada Pelepah ke-5 }\end{array}$} \\
\cline { 2 - 9 } Perlakuan & $3 \mathrm{bsp}$ & $6 \mathrm{bsp}$ & $3 \mathrm{bsp}$ & $6 \mathrm{bsp}$ & $3 \mathrm{bsp}$ & $6 \mathrm{bsp}$ & $3 \mathrm{bsp}$ & $6 \mathrm{bsp}$ \\
\cline { 2 - 9 } & tn & tn & tn & tn & tn & tn & tn & tn \\
\cline { 2 - 9 } $\mathrm{p}_{0} \mathrm{k}_{0}$ & 51.25 & 51.25 & 6.50 & 14.75 & 1.00 & 1.50 & 27.75 & 67.75 \\
$\mathrm{p}_{0} \mathrm{k}_{1}$ & 58.50 & 78.25 & 6.50 & 16.00 & 1.25 & 1.75 & 29.00 & 76.25 \\
$\mathrm{p}_{0} \mathrm{k}_{2}$ & 71.00 & 115.50 & 6.50 & 16.25 & 1.50 & 1.75 & 30.75 & 70.50 \\
$\mathrm{p}_{1} \mathrm{k}_{0}$ & 72.25 & 117.75 & 12.00 & 20.25 & 1.25 & 2.00 & 37.00 & 62.00 \\
$\mathrm{p}_{1} \mathrm{k}_{1}$ & 78.75 & 122.50 & 12.00 & 22.75 & 1.50 & 2.00 & 38.00 & 94.75 \\
$\mathrm{p}_{1} \mathrm{k}_{2}$ & 83.50 & 124.50 & 12.50 & 23.25 & 2.00 & 2.00 & 38.00 & 91.25 \\
$\mathrm{p}_{2} \mathrm{k}_{0}$ & 96.75 & 125.00 & 14.00 & 24.50 & 2.00 & 2.25 & 38.25 & 76.75 \\
$\mathrm{p}_{2} \mathrm{k}_{1}$ & 106.75 & 137.75 & 17.50 & 25.00 & 2.50 & 3.25 & 38.75 & 85.25 \\
$\mathrm{p}_{2} \mathrm{k}_{2}$ & 122.50 & 148.75 & 18.25 & 27.25 & 3.25 & 4.25 & 40.25 & 86.50 \\
\hline
\end{tabular}

Tabel 4. Pengaruh Interaksi Pupuk SP-36 dan KCl terhadap Tanaman Kakao Pada Rata-rata Pertambahan Tinggi Tanaman, Pertambahan Lingkar Batang dan Jumlah Buah Kakao

\begin{tabular}{ccccccc}
\hline & \multicolumn{2}{c}{$\begin{array}{c}\text { Pertambahan Tinggi } \\
\text { Tanaman }\end{array}$} & \multicolumn{2}{c}{\begin{tabular}{c} 
Pertambahan Lingkar \\
\multicolumn{2}{c}{ Batang }
\end{tabular}} \\
\cline { 2 - 7 } Perlakuan & $3 \mathrm{bsp}$ & $6 \mathrm{bsp}$ & $3 \mathrm{bsp}$ & $6 \mathrm{bsp}$ & $3 \mathrm{bsp}$ & $6 \mathrm{bsp}$ \\
\cline { 2 - 7 } & tn & tn & tn & tn & tn & tn \\
\hline $\mathrm{p}_{0} \mathrm{k}_{0}$ & 11.75 & 12.50 & 2.25 & 4.75 & 5.25 & 8.00 \\
$\mathrm{p}_{0} \mathrm{k}_{1}$ & 12.25 & 12.75 & 2.75 & 5.00 & 0.00 & 1.75 \\
$\mathrm{p}_{0} \mathrm{k}_{2}$ & 14.00 & 14.00 & 3.25 & 5.25 & 0.00 & 0.00 \\
$\mathrm{p}_{1} \mathrm{k}_{0}$ & 14.00 & 14.00 & 3.50 & 5.75 & 12.25 & 21.75 \\
$\mathrm{p}_{1} \mathrm{k}_{1}$ & 16.00 & 16.00 & 3.75 & 7.00 & 6.50 & 8.00 \\
$\mathrm{p}_{1} \mathrm{k}_{2}$ & 16.25 & 16.25 & 4.25 & 7.25 & 14.25 & 16.00 \\
$\mathrm{p}_{2} \mathrm{k}_{0}$ & 18.00 & 18.00 & 4.75 & 8.00 & 0.75 & 1.75 \\
$\mathrm{p}_{2} \mathrm{k}_{1}$ & 18.50 & 18.50 & 5.50 & 8.25 & 15.25 & 21.25 \\
$\mathrm{p}_{2} \mathrm{k}_{2}$ & 20.50 & 20.25 & 5.75 & 8.50 & 45.75 & 52.75 \\
\hline
\end{tabular}

\section{Pengamatan Intensitas Serangan Hama dan Penyakit Pada Buah Kakao}

Hasil pengamatan intesitas serangan hama dan penyakit pada buah kakao dapat dilihat pada Tabel 5. Berdasarkan hasil penelitian terhadap serangan hama pada buah kakao menunjukkan intensitas serangan hama pada buah kakao adalah $0.00-23.47 \%$ dan termasuk kedalam kategori rusak ringan. Sedangkan intensitas serangan penyakit pada buah kakao adalah 0.00 $66.30 \%$ dan termasuk kedalam kategori rusak sedang.

Tabel 5. Hasil Pengamatan Intensitas Serangan Hama dan Penyakit pada Buah Kakao

\begin{tabular}{ccc}
\hline & \multicolumn{2}{c}{ Intensitas Serangan } \\
\cline { 2 - 3 } Perlakuan & Hama & Penyakit \\
\hline $\mathrm{p}_{0} \mathrm{k}_{0}$ & 7.78 & 8.59 \\
$\mathrm{p}_{0} \mathrm{k}_{1}$ & 11.46 & 0.00 \\
$\mathrm{p}_{0} \mathrm{k}_{2}$ & 1.00 & 0.00 \\
$\mathrm{p}_{1} \mathrm{k}_{0}$ & 11.86 & 16.67 \\
$\mathrm{p}_{1} \mathrm{k}_{1}$ & 1.00 & 19.30 \\
$\mathrm{p}_{1} \mathrm{k}_{2}$ & 1.00 & 66.30 \\
$\mathrm{p}_{2} \mathrm{k}_{0}$ & 1.00 & 0.00 \\
$\mathrm{p}_{2} \mathrm{k}_{1}$ & 23.47 & 21.98 \\
$\mathrm{p}_{2} \mathrm{k}_{2}$ & 22.66 & 33.84 \\
\hline
\end{tabular}


Hama yang menyerang buah kakao adalah penggerek buah kakao Conopomorpha cramerella Snell. dan pengisap buah Helopeltis antonii (Hemiptera;Miridae). Serangan PBK dapat menyebabkan kerusakan buah dan kehilangan produksi biji sebesar 82,20\% (Depparaba, 2002). Sementara itu, H. antonii juga menyerang tunas-tunas muda atau pucuk, selain buah. Serangan berat dan berulang-ulang pada pucuk dapat menekan produksi kakao sekitar 36-75\% (Atmadja, 2003).

Serangan hama pada buah kakao pada perlakuan $\mathrm{p}_{2} \mathrm{k}_{1}$ memberikan intensitas serangan hama tertinggi yaitu $23.47 \%$. Hal ini disebabkan perlakuan pemupukan fosfor mempercepat pemasakan buah dan biji sehingga diserang oleh hama tikus dan tupai terutama pada malam hari. Serangan tikus terlihat adanya keratan pada buah berbentuk bulat awal serangan pada pangkal buah akibatnya buah menjadi kering dan tidak dapat di panen.

Penyakit yang menyerang buah kakao adalah penyakit busuk buah yang disebabkan oleh
Phythopthora palmivora. Phytophthora palmivora dapat menyebabkan kerugian yang cukup berarti terutama pada daerah beriklim tropis dan sedang. Penyakit ini tidak hanya menyerang buah, namun dapat juga menyerang bunga, bantalan bunga, batang, ranting muda, dan daun muda sehingga sangat mempengaruhi produksi dan kualitas buah kakao (Gregory, 1974).

Serangan penyakit busuk buah Phythopthora palmivora disebabkan penyebaran sporangium yang terbawa angina tau percikan air hujan dan penyakit akan berkembang dengan cepat.

Pada curah hujan yang tinggi semakin banyak jumlah buah yang terbentuk semakin tinggi jumlah serangan penyakit Phythopthora palmivora pada perlakuan p1k2 yaitu $66.30 \%$. Penyakit busuk buah Phythopthora palmivora dapat menyebabkan kehilangan hasil antara 20$30 \%$ per tahun, bahkan hingga besar dari $40 \%$ (Pusat Penelitian Kopi dan Kakao Indonesia, 2010).

\section{Analisa Kimia Tanah dan Identifikasi Mikroorganisme Tanah}

Hasil analisa kimia tanah dan identifikasi mikroorganisme tanah disajikan pada tabel tabel 6 .

Tabel 6. Hasil Analisa Kimia Tanah

\begin{tabular}{ccc}
\hline Variabel & Nilai & Kategori \\
\hline $\mathrm{pH}$ & 5.65 & Masam \\
C organik & 2.12 & Sedang \\
$\mathrm{N}$ & 0.31 & Sedang \\
$\mathrm{P}$ & 9.60 & Rendah \\
$\mathrm{K}$ & 113.3 & Tinggi \\
\hline
\end{tabular}

Tabel 7. Hasil Identifikasi Mikroorganisme

\begin{tabular}{ccc}
\hline Hasil Identifikasi & Jenis & Peranan \\
\hline Azotobacter & Bakteri & Biofertilizer \\
Bacillus & Bakteri & Biofertilizer \\
\hline
\end{tabular}


Beberapa mikroorganisme di dalam tanah berperan dalam siklus hara dan proses pembentukan tanah, pertumbuhan tanaman, mempengaruhi aktivitas mikroorganisme, serta sebagai pengendali hayati terhadap patogen akar.

Azotobacter merupakan kelompok bakteri yang dapat melakukan fiksasi Nitrogen di dalam tanah sehingga tergolong sebagai biofertilizer. Sedangkan Bacillus merupakan bakteri yang termasuk dalam kelompok Bakteri Pelarut Fosfat. Bakteri Pelarut Fosfat meliputi Pseudomonas sp., Bacillus sp., Bacillus megaterium, dan Chromobacterium sp. dapat dimanfaatkan sebagai biofertilizer dengan menghasilkan asam-asam organik yang dapat menggantikan $\mathrm{P}$ dalam ikatannya dengan $\mathrm{Al}$ ataupun $\mathrm{Fe}$ sehingga unsur $\mathrm{P}$ akan dilepaskan menjadi $\mathrm{P}$ larut yang dapat dimanfaatkan tanaman (Niswati et al. 2008).

\section{KESIMPULAN}

1. Perlakuan pupuk SP-36 berbeda sangat nyata terhadap tanaman aren genjah dan tanaman kakao pada semua variabel pengamatan pada tanaman aren genjah dan tanaman kakao pada umur 3 bsp dan 6 bsp. Perlakuan pupuk SP36 dengan dosis $0.5 \mathrm{~kg} \operatorname{tanaman}^{-1}$ (p2) memberikan pertumbuhan terbaik terhadap tanaman aren genjah umur 6 bsp pada pertambahan panjang pelepah ke-5, lingkar bonggol, jumlah pelepah dan jumlah anak daun pada pelepah ke-5 masing-masing yaitu $137.17 \mathrm{~cm}, 25.58 \mathrm{~cm}, 3.25$ helai dan 39.08 helai. Sedangkan pada tanaman kakao umur 6 bsp pupuk SP-36 dengan dosis $0.5 \mathrm{~kg}$ tanaman $^{-1}$ (p2) memberikan pertumbuhan terbaik pada pertambahan tinggi tanaman, lingkar batang dan jumlah buah kakao masing-masing yaitu $18.92 \mathrm{~cm}, 8.25 \mathrm{~cm}$ dan 25.25 buah.

2. Perlakuan pupuk $\mathrm{KCl}$ serta interaksi antara pupuk SP-36 dan pupuk $\mathrm{KCl}$ berbeda tidak nyata terhadap tanaman aren genjah dan tanaman kakao pada semua variabel pengamatan.

3. Hasil pengamatan serangan hama dan penyakit pada buah kakao dengan intensitas serangan hama $0.00-23.47 \%$ yang termasuk kedalam kategori rusak ringan dan intensitas serangan penyakit $0.00-66.30 \%$ yang termasuk kedalam kategori rusak sedang.

\section{UCAPAN TERIMA KASIH}

Penulis mengucapkan terima kasih kepada Fakultas Pertanian Universitas Mulawarman yang telah memberikan bantuan dana penelitian tahun 2018.

\section{DAFTAR PUSTAKA}

Argout., X, Salse. J., Aury, J., Guiltinan, M., Droc, G., Gouzy, J., Maximova, S. 2010. The genome of Theobroma cacao. Nat. Genet., 43, 101-108.

Azri. 2012. Teknologi Pemupukan Tanaman Kakao. Balai Pengkajian Teknologi Pertanian Kalimantan Barat. Pontianak. Kalbar.

Badan Penelitian dan Pengembangan Pertanian. 2011. http/www.litbang.deptan.go.id/ special/komoditas/kakao. Diunduh : 11 Nopember 2013.

Barker AV and DJ Pilbeam. 2007. Hand Book of Plant Nutrition. CRC Press. New York.

Barus. A. A. 2011. Pemanfaatan Pupuk Cair Mikro Untuk Meningkatkan Pertumbuhan dan Produksi Tanaman Sawi (Brassica juncea L.) Varietas Tosakan. Skripsi. Universitas Sumatera Utara.

Cuatrecasas, J. 1964. Cacao and Its Allies: A Taxonomic Revision of The Genus Theobroma (p. 613). Washington DC: Smithsonian Institution.

Darniaty Danial, Yossita Fiana, Fitri Handayani, M. Hidayanto. 2015. Peningkatan produksi dan mutu kakao melalui kegiatan Gernas di Kalimantan Timur. Prosiding Seminar Nasional Masyarakat Biodiversitas Indonesia. Volume 1, Nomor 5, Agustus 2015. 12031210.

Departemen Pertanian [Deptan]. 2009. Budidaya Dan Pengembangan Tanaman Enau. . www.http://deptan. [Diakses] tanggal 01/02/2014.

Dinas Perkebunan Provinsi Kalimantan Timur. 2013. Data Luas Areal dan Produksi Tanaman Aren. Dinas Perkebunan Provinsi Kalimantan Timur. Samarinda.

Effendi, D.S. 2009. Aren, Sumber Energi Alternatif. Warta Penelitian dan Pengembangan Pertanian. Tahun 2009.31(2):1-3.

Efombagen, M.I.B., Souniga, O., Eskes, A.B., Motamayor, J.C., Manzanares-Dauleux, M.J., Schnell, R., \& Nyasse, S. 2009. Parentage Analysis And Outcrossing Patterns in Cacao 
(Theobroma cacao L.) farms in Cameroon. Original Article. Heredity, 103, 46-53.

Fajariah, M. 2010. Produktivitas Pembuatan Gula Aren (arenga pinnata merr) dan Kontribusinya Terhadap Pendapatan Masyarakat Di Desa Guntung Kecamatan Haruyan Kabupaten Hulu Sungai Tengah. Skripsi. Fakultas Kehutanan. Universitas Lambung Mangkurat.

Hanafiah, K. A. 2005. Dasar-Dasar Ilmu Tanah. Universitas Sriwijaya. Palembang.

International Cocoa Organization. 2003. Products that can be made from cocoa. Retrieved from http://www.icco.org/faq/52by-products/115- products-that-can-bemade-from-cocoa.html International Cocoa Organization. (2011). Origins of cocoa and its spread around the world. Retrieved from http://www.icco.org/aboutcocoa/ growingcocoa.html.

Kartasapoetra, A. G. dan Sutedjo. 2005. Pupuk dan Cara Pemupukannya. Rineka Cipta, Jakarta.

Maliangkay, R.B.2007. Teknik Budidaya dan Rehabilitasi Tanaman Aren.Buletin Palma No.33, 67-77.

Manggabarani, A. 2011. Konsepsi Gerakan Peningkatan Produksi dan Mutu Kakao (Gernas Kakao). Seminar Evaluasi Pelaksanaan Gernas Kakao BAPPENAS tanggal 27 Januari 2011, Jakarta.

Miller, R.H. 1964. The Versatile Sugar Palm. Principes Journal of The Palm Society. 8(4) : 115-146.

Motilal, L.A., Zhang, D., Umaharan, P., Mischke, S., Mooleedhar, V., \& Meinhardt, L.W. 2010. The relic Criollo cacao in Belizegenetic diversity and relationship with Trinitario and other cacao clones held in the International Cocoa Genebank, Trinidad. Plant Genetic Resources: Characterization and Utilization, 8(2), 106- 115.

Novizan. 2005. Pupuk Pemupukan Yang Efektif. Agromedia. Jakarta.

Purwa, D. R. 2007. Petunjuk Pemupukan. Agro Media Pustaka. Jakarta.

Pusat Penelitian Kopi dan Kakao Indonesia. 2010. Buku Pintar Budidaya Kakao. Jakarta: Agro Media Pustaka.
Rosmarkam, A. dan N. W. Yuwono. 2002. Ilmu Kesuburan Tanah. Kanisius. Yogyakarta. 224 hlm.

Silalahi, F., Y. Saragih, A. Marpaung, R. Hutabarat, Karsina, \& S. R. Purba. 2006. Laporan Akhir Uji Pemupukan NPK Pada Tanaman Buah. Balai Penelitian Buah Kebun Percobaan Tanaman Buah (KPTB), Brastagi. Medan.

Smits. W.T.M. 1993. Arenga pinnata (Wurmb) Merr. In. E. Westphal and P.C.M Jansen, (Eds.). A. Selection. Plant Resources of South-East Asia (PROSEA). Pudoc. Wageningan. $322 \mathrm{p}$.

1996. Arenga pinnata (Wurmb) Merr. In. M. Flach and F. Rumawas, (Eds). Plant Yielding Non-Seed Carbohydrates Plant Resources of South East Asia No. 9. Bogor. Indonesia. 53-59 p.

Sutedjo, M. M. 2002. Pupuk dan Cara Pemupukan. Penerbit Rineka Cipta. Jakarta.

Steel, R.G.D. and J.H.Torrie. 1991. Prinsip dan prosedur statistika (Terjemahan B. Sumantri ). Gramedia Pustaka Utama. Jakarta.

Taiz, L., \& Zeiger. 2002. Plant Physiologi. Massachusetts: Sinauer Associates Inc. Publisher.

Thomas, E., van Zonneveld, M., Loo, J., Hodgkin, T., Galluzzi, G., \& van Etten, J. 2012. Present spatial diversity patterns of Theobroma cacao L. In the neotropics reflect genetic differentiation in pleistocene refugia followed by human-influenced dispersal.

Tuherkih, E. dan I.A. Sipahutar. 2008. Pengaruh pupuk NPK majemuk (16:16:15) terhadap pertumbuhan dan hasil jagung (Zea mays L) di tanah inceptisols. Hal 77-88. Balai Penelitian Tanah.

Vassilev, N; Medina, A; Azcon dan R. Vassileva. 2006. Microbial solibilization of rock phosphate on media containing agroindustrial wastes and effect of the resulting product on plant growth and $P$ uptake. Plant Soil. 287: 77-84.

Wood, G.A.R., \& Lass, R.A. 1985. Cocoa. New York: Longman Inc. 